\title{
Antitumor effects of herbal mixture extract in the pancreatic adenocarcinoma cell line PANC1
}

\author{
PYO JUNE PAK ${ }^{1 *}$, BEOB HWA KANG ${ }^{*}$, SUNG HYO PARK $^{2}$, JI HYUN SUNG $^{2}$, \\ YONG HOON JOO ${ }^{1}$, SEUNG HYUN JUNG ${ }^{3}$ and NAMHYUN CHUNG ${ }^{1}$ \\ ${ }^{1}$ Department of Biosystems and Biotechnology, College of Life Sciences and Biotechnology, Korea University, Seoul 02841; \\ ${ }^{2}$ Biomedical Research Institute, Seoul National University Hospital, Seoul 03080; \\ ${ }^{3}$ School of Oriental Medicine, Dongguk University, Goyang 10326, Republic of Korea
}

Received March 29, 2016; Accepted August 10, 2016

DOI: $10.3892 /$ or.2016.5067

\begin{abstract}
A recent study showned that complementary medicine is gradually gaining wide acceptance. In the present study, the herbal mixture extract (H3) composed of 3 oriental herbal plants was investigated for anticancer activity in vitro and in vivo. $\mathrm{H} 3$ inhibited $\mathrm{PANC} 1$ cell growth by promoting G0/G1 arrest (11\% increase) and apoptotic cell death (9\% increase). $\mathrm{H} 3$ also suppressed stem cell-like side population cells (4\% decrease) and migration activity (24\% decrease). In contrast, gemcitabine decreased side population cells and migration activity by 3 and $11 \%$, respectively. These effects of $\mathrm{H} 3$ and gemcitabine were further studied by examining the expression of apoptosis-associated genes (CXCR4, JAK2 and XIAP) and stem cell-associated genes (ABCG2, POU5F1 and SOX2). We also found that H3 suppressed tumor growth by $46 \%$ in a PANC1-xenograft model, while gemcitabine caused a $36 \%$ decrease. The antitumor effects of H3 were confirmed by western blot analysis for COX-2 and cytochrome $c$ expression. Furthermore, necrotic cell death and erythrocyte-containing cavities were detected in tumor tissue by hematoxylin and eosin (H\&E) staining. Notably, the combinatorial therapy (H3 and gemcitabine) increased tumor growth compared to that in the control. In conclusion, the present study shows that $\mathrm{H} 3$ has promise as a therapeutic agent against pancreatic cancer and its cancer stem cells.
\end{abstract}

Correspondence to: Professor Namhyun Chung, Department of Biosystems and Biotechnology, College of Life Sciences and Biotechnology, Korea University, Seoul 02841, Republic of Korea E-mail: nchung@korea.ac.kr

${ }^{*}$ Contributed equally

Key words: cancer stem cell, pancreatic cancer, traditional medicinal herb, side population, xenograft model

\section{Introduction}

Pancreatic cancer is ranked fourth among cancer-related deaths worldwide and has a 5-year survival rate $\sim 5 \%$ (1). This is likely due to an inadequate response with the currently available treatments along with late detection, to the aggressive pathogenesis course of the disease, and to the development of extreme resistance to radiation, chemotherapies, targeting agents or a combination of these $(1,2)$. Thus, there is a steady movement of ongoing research on various promising therapies for pancreatic cancer (3-5). Gemcitabine is a widely used therapy to treat patients with pancreatic cancer $(6,7)$. Gemcitabine affects the $S$ phase of cell cycle, preventing cell division, and has proven to be effective for symptom management and prolonged survival in advanced pancreatic cancer (8). Recent clinical trials of combination therapy with gemcitabine and another agent had statistical significance, but not significant enough for patients (9-11).

The use of traditional herbal medicines, such as extracts of herbal mixtures, has been revisited since these medicines often present anticancer activities with no or less adverse side-effects (12). Herbal mixture extracts have been studied in pancreatic cancer, as well as other types of cancers $(5,13,14)$. Cocktail therapies of herbal mixture extracts and antitumor drugs may have synergistic effects against tumor growth, allowing the use of lower doses of anticancer drug (15). Thus, the combinatorial use of a herbal mixture and an anticancer drug is of great interest to enhance the beneficial effects of cancer chemotherapeutics.

The present study assesses the antitumor effect of an herbal mixture extract (H3) in the pancreatic adenocarcinoma cell line PANC1 and in a PANC1-induced heterotopic xenograft model. These effects were compared to those of gemcitabine alone and to a H3-gemcitabine combinatorial therapy.

\section{Materials and methods}

Preparation of H3. H3 was composed of $40 \%$ Meliae fructus (China), 40\% Cinnamon bark (Vietnam) and $20 \%$ Sparganium rhizome (China) that were obtained from the Oriental Medical Hospital, Dongguk University (Korea). H3 
was prepared as follows: the dried and pulverized medicinal herbs were mixed together in $8 \mathrm{~kg}$ batches and were soaked in $40 \%$ ethanol (80 1). The ethanol extract was concentrated using a rotary evaporator, lyophilized and reconstituted in distilled water.

In vitro experiment. The human pancreatic cancer cell line (PANC1; KCLB \#21469) was purchased from the Korean Cell Line Bank (KCLB; Seoul, Korea). PANC1 was cultured in Dulbecco's modified Eagle's medium (DMEM) supplemented with 10\% fetal bovine serum (FBS) (both from WelGENE Inc., Daegu, Korea), $100 \mathrm{U} / \mathrm{ml}$ penicillin and $100 \mu \mathrm{g} / \mathrm{ml}$ streptomycin. The cells were maintained in a humidified incubator at $37^{\circ} \mathrm{C}$ containing $5 \% \mathrm{CO}_{2}$. PANC1 cells were seeded in cell culture plates (Sarstedt Inc., Nuermbrecht, Germany) at a density of $5 \times 10^{5}$ cells. The cells were treated with $\mathrm{H} 3(0.07 \mathrm{mg} / \mathrm{ml})$ or gemcitabine $(10 \mathrm{nM}$; Sigma-Aldrich, St. Louis, MO, USA). For co-treatment, the cells were treated sequentially with $0.05 \mathrm{mg} / \mathrm{ml}$ of $\mathrm{H} 3$ and $3 \mathrm{nM}$ of gemcitabine, with a $2 \mathrm{~h}$ interval between the two treatments. After a $72 \mathrm{~h}$ incubation, the cells were harvested using $0.05 \%$ trypsin-EDTA.

Animal model. Five-week-old female BALB/c-nu/nu mice (Nara Biotech Co., Seoul, Korea) with body weights between 18-20 g were used in the present study. All animals were maintained in standard conditions under $12 \mathrm{~h}$ light and $12 \mathrm{~h}$ dark cycle, and allowed to acclimate for a week prior to the start of the study. All procedures were approved by the Internal Animal Care and Use Committee, Korea University (KUIACUC-2014-218).

The xenograft models were created by injection of human tumor cells using the methods described by Kim et al (16). The mice were randomly divided into 4 groups, each experimental group contained 5 mice. H3 was administered orally every 6 days and gemcitabine hydrochloride salt (Eli Lilly and Company, Indianapolis, IN, USA) was administered by intraperitoneal (IP) injection every 3 days. Tumor volumes and body weights were measured 3 times a week. Tumor volumes were calculated by the formula of $(\alpha \times 2 b) \times 0.5$, where $\alpha$ and $\mathrm{b}$ are the long and short dimensions, respectively. Inhibition of tumor growth was expressed as the T/C ratio, the ratio of the median tumor volume in the treated vs. the control group.

In vitro assays. Cell viability was determined by trypan blue dye exclusion assay. Cell cycle and apoptosis analysis were performed using the methods described by Jung et al (17). Analysis of the side population (SP) has been previously described by Goodell et al (19). SP cells are a small population of stem cell-like cells that stain faintly or not at all upon treatment with Hoechst 33342 dye. Verapamil was used to confirm the SP as it blocks the ABC transporters leading to a disappearance of the SP phenotype. Briefly, after drug treatment, PANC1 cells were incubated with Hoechst 33342 dye $(5 \mu \mathrm{g} / \mathrm{ml})$ in the presence or absence of verapamil $(50 \mu \mathrm{M} / \mathrm{l})$ (both from Sigma-Aldrich). The cells were analyzed and the SP was sorted using FACSAria (BD Biosciences, San Jose, CA, USA).

The CytoSelect 24-Well Wound Healing assay (Cell Biolabs, San Diego, CA, USA) was used to analyze PANC1
Table I. The composition of H3.

\begin{tabular}{llcr}
\hline Oriental name & $\begin{array}{c}\text { Country of } \\
\text { origin }\end{array}$ & $\begin{array}{c}\text { Grams of } \\
\text { dried materials }\end{array}$ & $\%$ \\
\hline Meliae fructus & China & 3,200 & 40 \\
Cinnamon bark & Vietnam & 3,200 & 40 \\
Sparganium rhizome & China & 1,600 & 20 \\
Total amount & & 8,000 & 100 \\
\hline
\end{tabular}

$\mathrm{H} 3$, herbal mixture extract. H3 is composed of 3 oriental medicinal herbs. The herbal ingredients were obtained from the Oriental Medical Hospital of Dongguk University (Ilsan, Korea).

migration. The assay was performed according to the manufacturer's protocol.

For the analysis of transcriptional levels, total RNA was isolated from cells using RNAeasy (Qiagen, Valencia, CA, USA), followed by first strand cDNA synthesis using Reverse Transcription System (Promega, Madison, WI, USA) as directed by the manufacturer's instruction. Real-time PCR was performed using TaqMan Gene expression master mix and TaqMan Gene expression assay (both from Applied Biosystems, Foster City, CA, USA). GAPDH was used as an internal control. The real-time PCR was performed using CFX-96 (Bio-Rad, Hercules, CA, USA). The PCR cycle conditions were $95^{\circ} \mathrm{C}$ for $10 \mathrm{~min}$ followed by 50 cycles of $95^{\circ} \mathrm{C}$ for $15 \mathrm{sec}$ and $60^{\circ} \mathrm{C}$ for $1 \mathrm{~min}$. Each analysis was performed in triplicate. Gene expression was quantified using the $2^{-\Delta \Delta C t}$ method and normalized vs. the expression of the housekeeping gene GAPDH.

In vivo assay. Tumors were excised and fixed with $4 \%$ formaldehyde. Fixed tumors were embedded in paraffin. Paraffin-embedded sample slides were deparaffinized, hydrated and stained with hematoxylin. After rinsing, the slides were stained with eosin, rinsed and sealed with coverslips using Canada balsam. Stained samples were examined and photographed using an Olympus CK40 microscope (Olympus, Tokyo, Japan).

Tumor sample protein extracts were separated by sodium dodecyl sulfate-polyacrylamide gel electrophoresis (SDS-PAGE) and transferred to a polyvinylidene fluoride (PVDF) membrane $(0.45 \mu \mathrm{m}$; EMD Millipore, Billerica, MA, USA). The membrane was blocked with 5\% skim milk and incubated overnight with primary antibodies at $4^{\circ} \mathrm{C}$. Primary antibodies against COX-2, cytochrome $c$ and $\beta$-actin were purchased from Cell Signaling Technology (Danvers, MA, USA). After washing, horse-radish peroxidase (HRP)-conjugated secondary antibodies (Santa Cruz Biotechnology, Inc., Santa Cruz, CA, USA) were applied. The blots were visualized using the enhanced chemiluminescence (ECL) Western Blotting Detection Reagents (Thermo Fisher Scientific, Inc., Waltham, MA, USA).

Statistical analysis. Data are expressed as means \pm standard error (SE) of at least 3 independent experiments. Statistical analyses were performed using the SPSS 20.0 software 

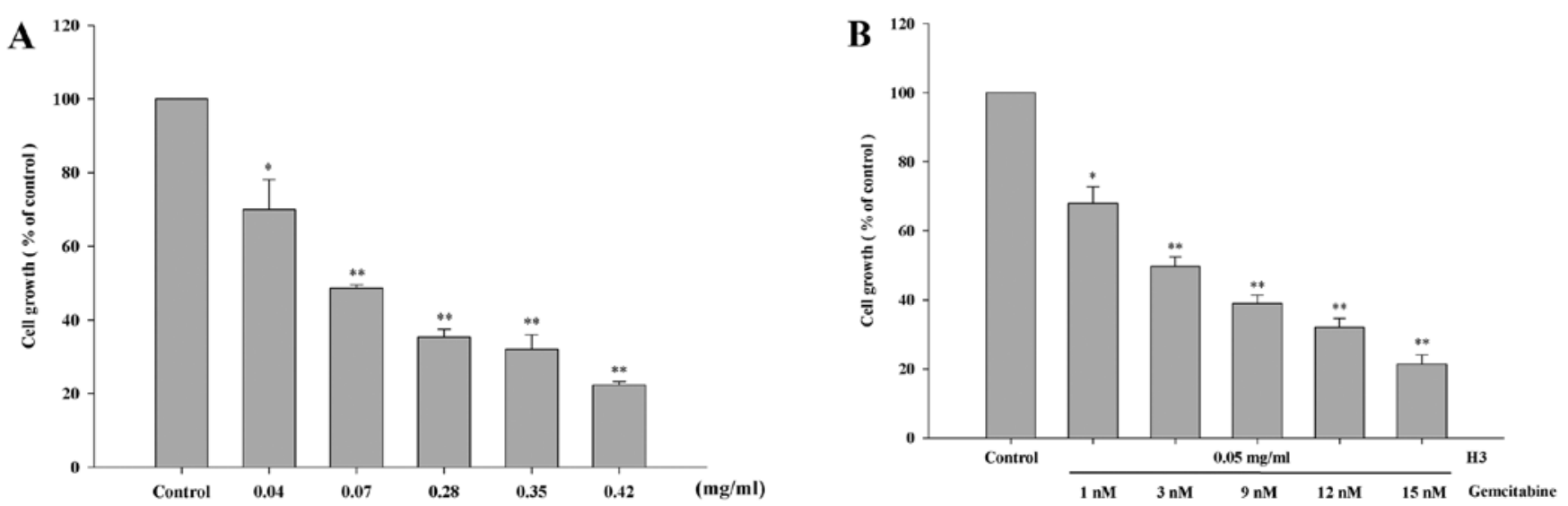

Figure 1. Effect of $\mathrm{H} 3$ and gemcitabine on PANC1 cell growth. (A and B) PANC1 cells were treated for $72 \mathrm{~h}$ with $\mathrm{H} 3$ or with $\mathrm{H} 3$-gemcitabine. The cell viability was determined by trypan blue dye exclusion assay. The data were normalized to the control. Data are expressed as the mean $\pm \mathrm{SE}$ of 3 independent experiments; ${ }^{*} \mathrm{p}<0.05,{ }^{* *} \mathrm{p}<0.01$ against control.

A
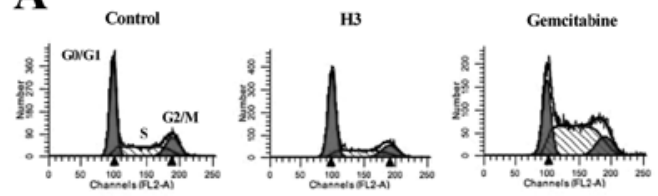

B

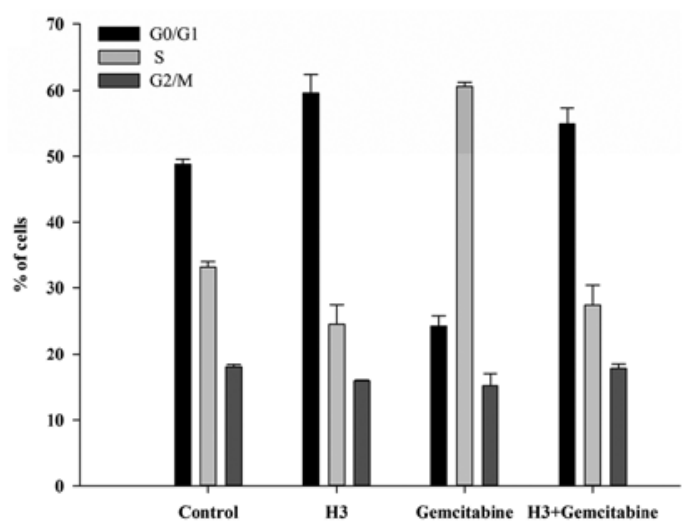

C


D

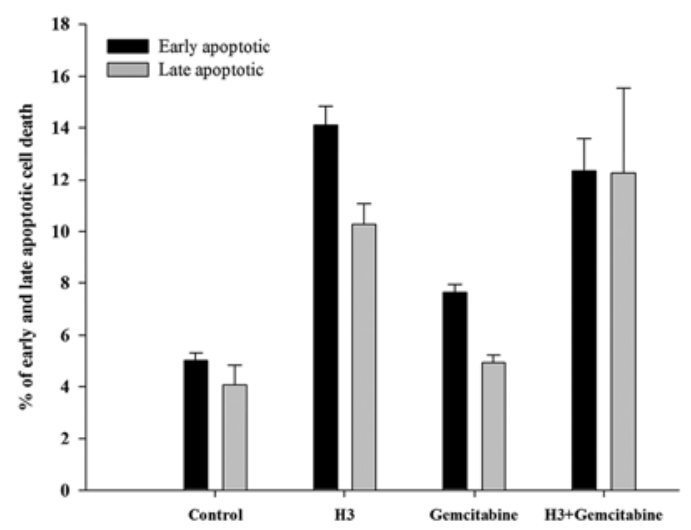

Figure 2. Effect of $\mathrm{H} 3$ and gemcitabine on cell cycle progression and apoptosis of PANC1 cells. (A and B) The cells were treated with $0.05 \mathrm{mg} / \mathrm{ml}$ of $\mathrm{H} 3 \mathrm{in}$ the absence or presence of $3 \mathrm{nM}$ gemcitabine for $72 \mathrm{~h}$, followed by cell cycle analysis via flow cytometry. The proportions of the population in the different cell cycle phases were quantified from the profiles in (A). (C and D) After treatment with $\mathrm{H} 3$ and/or gemcitabine for $72 \mathrm{~h}$, PANC1 cells were stained with Annexin V-FITC and PI, and analyzed with the FACSCalibur system. Data are expressed as the mean \pm SE of 3 independent experiments.

(IBM Corp., Armonk, NY, USA). Statistical significance was determined using Student's t-test or Mann-Whitney U test for comparisons between two means at p-value $<0.05$ or 0.01 .

\section{Results}

H3 inhibits PANC1 cell growth. $\mathrm{H} 3$ is the ethanol extract of a mixture of Meliae fructus, Cinnamon bark and Sparganium rhizome (Table I). To examine the cytotoxic effects of this herbal mixture extracts (H3) in PANC1 cells, we used the trypan blue exclusion assay. Both $\mathrm{H} 3$ and $\mathrm{H} 3$-gemcitabine inhibited the growth rate in a dose-dependent manner (Fig. 1). We hypothesized that co-treatment would allow the use of lower concentrations of anticancer drug leading to less harmful side-effects. Thus, the concentration of gemcitabine was varied after fixing the concentration of $\mathrm{H} 3$. The half-maximal inhibitions $\left(\mathrm{IC}_{50}\right)$ of proliferation were $0.07 \mathrm{mg} / \mathrm{ml} \mathrm{H} 3,10 \mathrm{nM}$ gemcitabine or $0.05 \mathrm{mg} / \mathrm{ml}$ $\mathrm{H} 3$ with $3 \mathrm{nM}$ gemcitabine (co-treatment). The $\mathrm{IC}_{50}$ value of gemcitabine was obtained by Park et al (18). These data indicate that $\mathrm{H} 3$ inhibits PANC1 cell growth at the relatively low concentration of $0.07 \mathrm{mg} / \mathrm{ml}$.

H3 affects cell cycle arrest and apoptotic cell death. After $\mathrm{H} 3$ treatment, the PANC1 cells were fixed in 99\% cold ethanol for cell cycle progression. Treatment with $\mathrm{H} 3$ led PANC1 cells to cell cycle arrest at the G0/G1 phase $(59.6 \pm 3.9 \%)$ with a concomitant reduction in the percentage of cells in the $\mathrm{S}$ and $\mathrm{G} 2 / \mathrm{M}$ phase, compared with the values for the control (48.8 $\pm 1.1 \%$; Fig. $2 \mathrm{~A}$ and B). When the cells were treated with $\mathrm{H} 3$ and gemcitabine (co-treatment), the increase in the percentage of cells in the G0/G1 phase $(54.9 \pm 3.4 \%)$ 

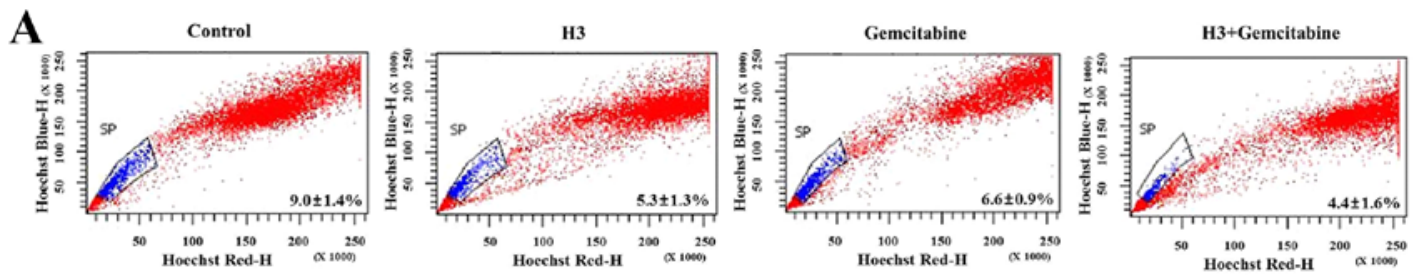

B

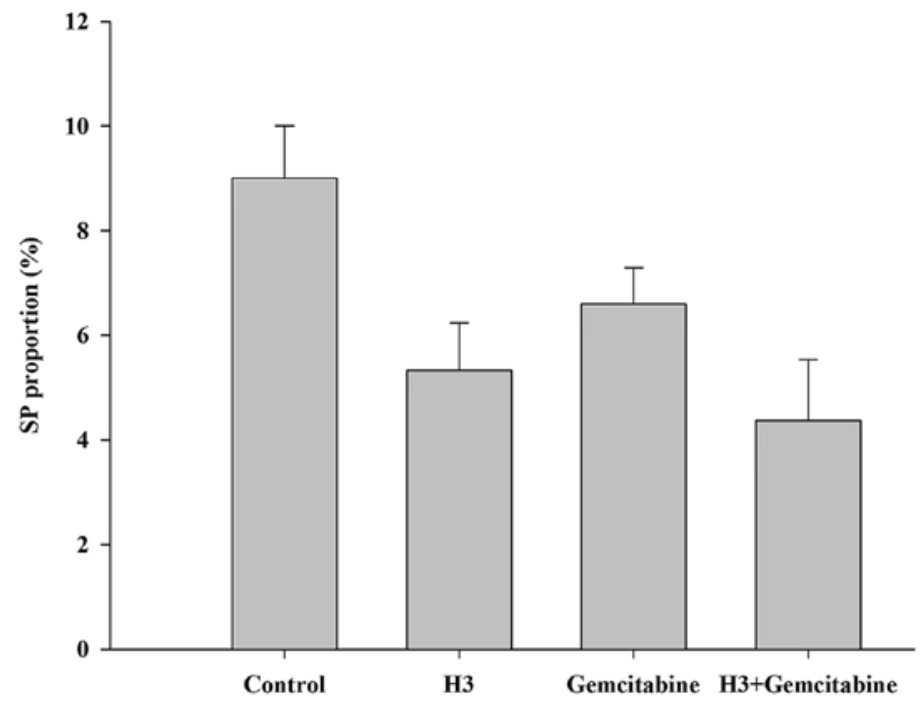

Figure 3. Analysis of the PANC1 SP after treatment with $\mathrm{H} 3$ and/or gemcitabine. PANC1 cells were treated for $72 \mathrm{~h}$. (A) Th SP fraction was analyzed in the presence of $5 \mu \mathrm{g} / \mathrm{ml}$ Hoechst 33342 with or without $50 \mu \mathrm{M} / 1$ verapamil, an ABC transporter inhibitor, using a FACSAria. The data from one representative experiment out of 3 independent experiments is shown. The proportion of SP cells is shown in (B). Data are expressed as the mean \pm SE of 3 independent experiments.

was slightly lower than with $\mathrm{H} 3$ treatment. In contrast, gemcitabine induced S phase arrest in $60.6 \pm 0.9 \%$ of cells, which is much higher than the percentage seen in the control population (33.2 $\pm 1.2 \%$; Fig. 2B).

We examined apoptotic cell death in cells treated with $\mathrm{H} 3$ and/or gemcitabine. Cell death was evaluated by double-staining with Annexin V-FITC and PI. The percentage of early apoptotic cell death was $14.1 \pm 0.7 \%$ with $\mathrm{H} 3$ treatment, compared to $5.0 \pm 0.3 \%$ in the control group (Fig. $2 \mathrm{C}$ and D). The percentage of early apoptotic cell death was $12.4 \pm 1.2 \%$ with co-treatment, which is slightly lower than with $\mathrm{H} 3$. The percentage of late apoptotic cell death by co-treatment was $12.3 \pm 3.3 \%$, which was slightly higher than with $\mathrm{H} 3$ only $(10.3 \pm 0.8 \%)$ or in the control $(4.1 \pm 0.8 \%)$. However, with gemcitabine treatment, the percentage of early and late apoptotic cell death was $7.6 \pm 0.3$ and $4.9 \pm 0.3 \%$, respectively, which was lower than with $\mathrm{H} 3$ only and co-treatment.

H3 suppresses SP cells. To examine the inhibitory effect of $\mathrm{H} 3$ and/or gemcitabine in cancer stem cells, we performed an SP assay. The ABC transporter inhibitor verapamil was administered in order to confirm SP cells (19). The SP gate was determined by the disappearance of the cell population in the presence of verapamil. The difference in the percentage of SP cells between the control $(9.0 \pm 1.4 \%)$ and $\mathrm{H} 3(5.3 \pm 1.3 \%)$ treatment groups was $\sim 3.7 \%$. With co-treatment $(4.4 \pm 1.6 \%)$, the percentage of SP cells decreased even further. However, with gemcitabine treatment $(6.6 \pm 0.9 \%)$, the percentage of $\mathrm{SP}$ cells was greater than with $\mathrm{H} 3$ only and co-treatment, indicating that gemcitabine is less effective than the other

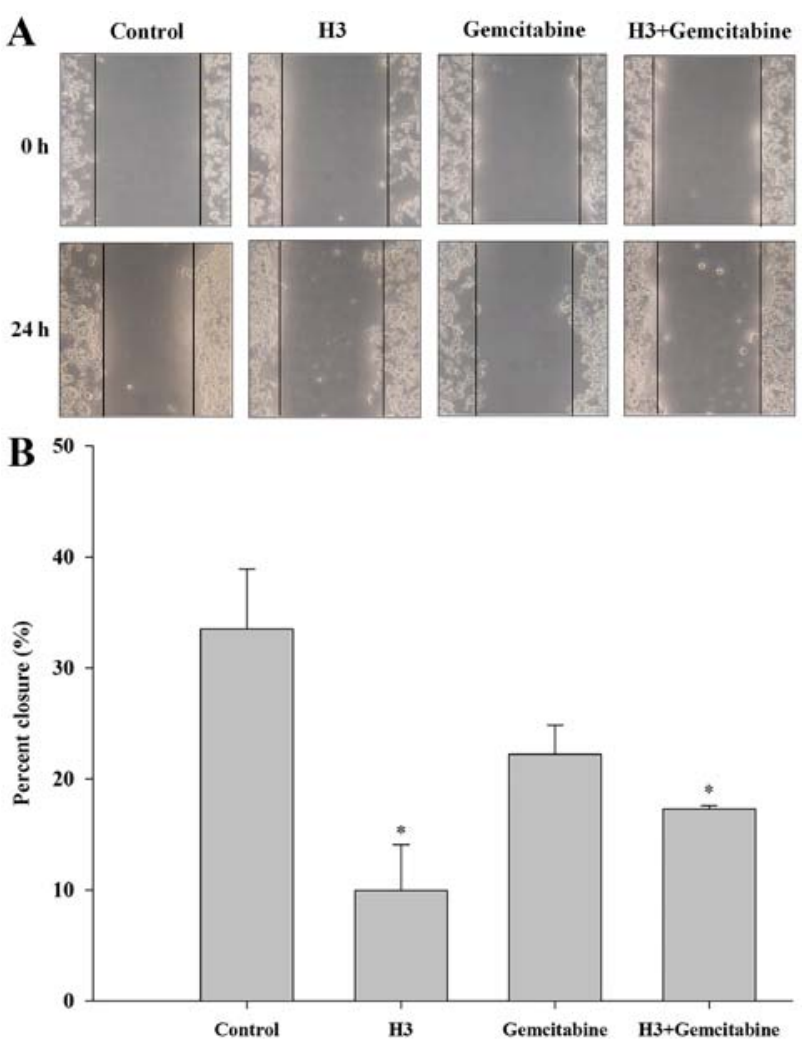

Figure 4. Effect of $\mathrm{H} 3$ and gemcitabine on the migration mobility of PANC1 cells. (A) Wound healing assays were carried out. Wound fields were observed promptly after removal of inserts $(0 \mathrm{~h})$ and cell migration was observed after $24 \mathrm{~h}$. (B) Migration activities were measured by the percent closure of PANC1 cells into the wound field. Data are expressed as the mean $\pm \mathrm{SE}$ of 3 independent experiments; ${ }^{*} \mathrm{p}<0.05$, compared to control. 
A



B



C

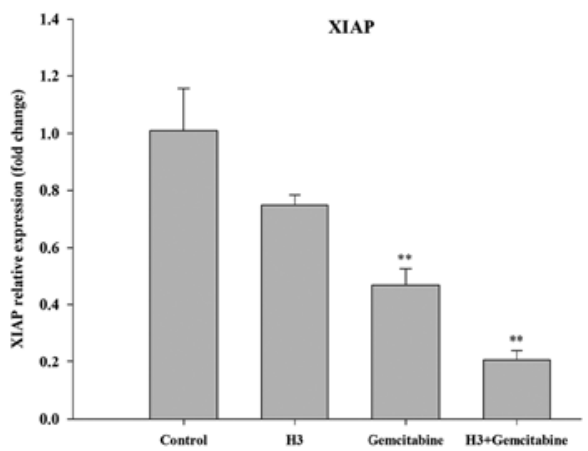

Figure 5. Quantification of the mRNA levels of apoptosis-associated genes after treatment with $\mathrm{H} 3$ and/or gemcitabine. PANC1 cells were treated for $72 \mathrm{~h}$. The mRNA levels of (A) CXCR4, (B) JAK2 and (C) XIAP were determined by real-time RT-PCR. The values were obtained by normalizing to the GAPDH internal control. Data are expressed as the mean \pm SE of thee independent experiments; ${ }^{*} \mathrm{p}<0.05,{ }^{* *} \mathrm{p}<0.01$, compared to control.

A

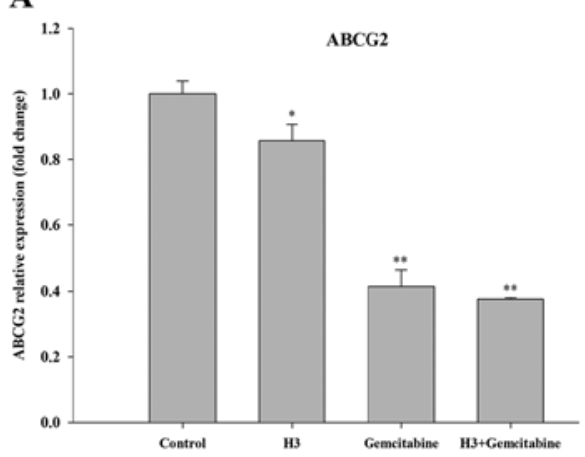

B

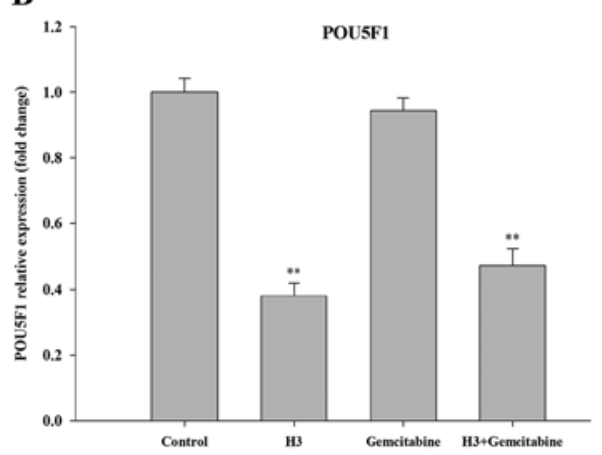

C

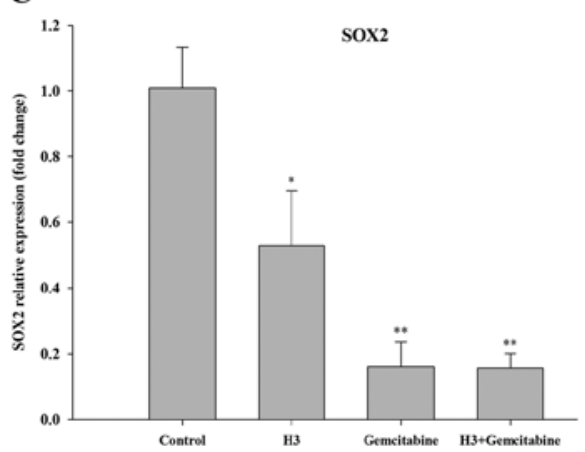

Figure 6. Quantification of the mRNA levels of stem cell-related genes after treatment with $\mathrm{H} 3$ and/or gemcitabine. PANC1 cells were treated for $72 \mathrm{~h}$. The mRNA levels of (A) ABCG2, (B) POU5F1 and (C) SOX2 were determined by real-time RT-PCR. The values were obtained by normalizing to the GAPDH internal control. The results are expressed as the mean $\pm \mathrm{SE}$ of 3 independent experiments; ${ }^{*} \mathrm{p}<0.05,{ }^{* *} \mathrm{p}<0.01$, compared to control.

treatments (Fig. 3). Thus, among the 3 treatments, co-treatment with H3-gemcitabine is most effective at inhibiting SP cells.

H3 inhibits migration ability. After treatment with $\mathrm{H} 3$ and/or gemcitabine, the migration activity was measured using a wound healing assay. The percent of closure was much lower in the H3-treated cells than in the control (9.9 vs. $33.5 \%$, respectively; Fig. 4). The percent of closure followed the order: control $(33.5 \%)>$ gemcitabine only $(22.2 \%)>$ co-treatment $(17.3 \%)>\mathrm{H} 3$ only $(9.9 \%)$, indicating that $\mathrm{H} 3$ treatment is most effective at inhibiting the migration activity of PANC1 cells.

H3 decreases the MRNA expression of apoptosis-associated genes. As $\mathrm{H} 3$ induced apoptotic cell death, we investigated the effect of $\mathrm{H} 3$ on the mRNA expression of apoptosis-associated genes. After treatment with $\mathrm{H} 3$ and/or gemcitabine, the mRNA levels of apoptosis-related genes was analyzed by RT-PCR. As shown in Fig. 5A, treatment with $\mathrm{H} 3$ and co-treatment with H3-gemcitabine significantly decreased CXCR4 mRNA levels by $\sim 57$ and $69 \%$, respectively. JAK2 mRNA levels were reduced by $\sim 56$ and $58 \%$ with $\mathrm{H} 3$ and co-treatment treatment, respectively (Fig. 5B). With co-treatment XIAP mRNA levels were markedly inhibited by $\sim 80 \%$, but the effects were markedly less with $\mathrm{H} 3$ treatment only (Fig. 5C).

H3 decreases the mRNA levels of stem cell-related genes. As $\mathrm{H} 3$ suppressed the percentage of SP cells, we investigated the effect of $\mathrm{H} 3$ on the mRNA accumulation of stem cell-related genes. Following $\mathrm{H} 3$ and/or gemcitabine treatment, the mRNA levels of stem cell-associated genes were analyzed by RT-PCR. As shown in Fig. 6A, gemcitabine treatment and co-treatment strongly decreased the levels of ABCG 2 mRNA by $\sim 56$ and $58 \%$, respectively. The level of ABCG 2 mRNA with H3 was less significant $(15 \%)$ than with gemcitabine treatment and co-treatment. The extent of suppression was statistically lower than that of the control. H3 treatment and co-treatment decreased POU5F1 mRNA levels by $\sim 62$ and $53 \%$, respectively (Fig. 6B). All the 3 treatments strongly suppressed SOX2 mRNA levels, but the suppression was more significant with gemcitabine treatment and co-treatment ( $\sim 85 \%$ each) than with $\mathrm{H} 3$ treatment ( 48\%; Fig. $6 \mathrm{C})$.

H3 suppresses PANCl-induced tumor growth in vivo. The tumor volumes of control, H3, gemcitabine and co-treated mice at day 31 were $\sim 160.5,113.1,109.6$ and $267.4 \mathrm{~mm}^{3}$, respectively (Fig. 1A and B). The tumor growth was less in 



D

\section{Control}

H3

Gemcitabine

H3+Gemcitabine
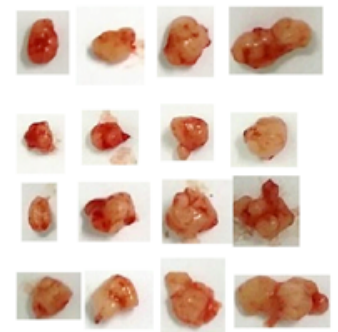

Figure 7. Inhibition of tumor growth in a pancreatic xenograft model after treatment with $\mathrm{H} 3$ and/or gemcitabine. (A) PANC1 pancreatic cancer cells $\left(1.5 \times 10^{6}\right)$ were subcutaneously injected in nude mice randomly divided into groups $(n=5)$. The following concentrations of drugs were administered for 31 days: $\mathrm{H} 3$ $(200 \mathrm{mg} / \mathrm{kg})$, gemcitabine $(100 \mathrm{mg} / \mathrm{kg})$, and co-treatment of $\mathrm{H} 3(100 \mathrm{mg} / \mathrm{kg})$ and gemcitabine $(50 \mathrm{mg} / \mathrm{kg})$. (B) The inhibition rates of tumor growth at day 31 are expressed as $\mathrm{T} / \mathrm{C}$ ratios (ratio of relative mean tumor volume of the treated group/relative mean tumor volume of the control group). (C) Body weights were measured 3 times a week. (D) Representative tumor images from each treatment group. Data are expressed as the mean $\pm \mathrm{SE}$.

A
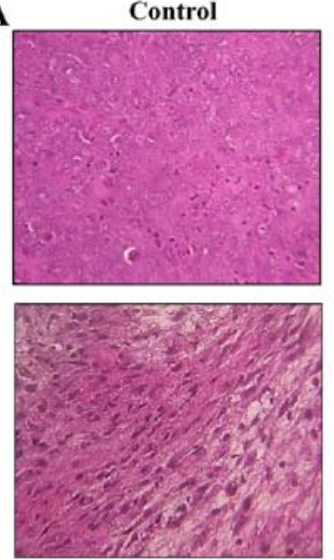

Gemcitabine


H3+Gemcitabine
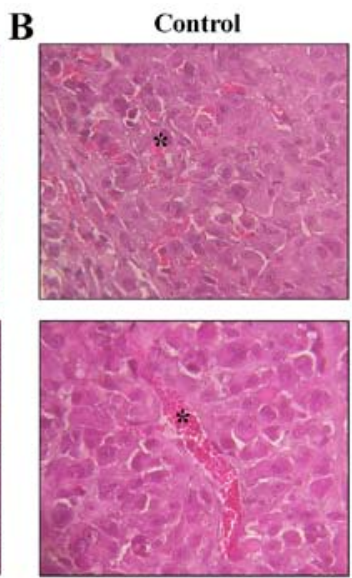

Gemcitabine


H3+Gemcitabine

Figure 8. Histological analysis of tumor tissue samples from each treatment group. Tumor tissues were stained with H\&E staining. Images were captured at a magnification of $x 400$. The necrotic cell death of tumor tissue samples are shown in (A). (B) In some areas, erythrocytes $(*)$ are visible within tumor cell-lined cavities.

$\mathrm{H} 3$ only- and gemcitabine-treated mice than in the control group, and there was not much difference between the $\mathrm{H} 3$ group or gemcitabine group. However, the tumor growth was much greater in the co-treated mice than in the other groups (Fig. 7A, B and D). No significant differences in body weight were observed between the groups (Fig. 7C). To quantify the treatment effects in the tumor xenograft experiments, the $\mathrm{T} / \mathrm{C}$ ratio was used as an antitumor activity rating. It uses an arbitrary cutoff point and typically has no formal statistical inference (20). The tumor inhibition rates of each treatment group were as follows: control $(\mathrm{T} / \mathrm{C}$ ratio $=1.00), \mathrm{H} 3$ $(\mathrm{T} / \mathrm{C}$ ratio $=0.54)$, gemcitabine $(\mathrm{T} / \mathrm{C}$ ratio $=0.64)$, co-treatment $(\mathrm{T} / \mathrm{C}$ ratio $=2.00)$. Consequently, the tumor inhibition rate of the $\mathrm{H} 3$ treatment was greater than all the other groups (Fig. 7B).

The antitumor effects of $\mathrm{H} 3$ occur through $\mathrm{COX}-2$ and cytochrome c-mediated apoptotic cell death. Induction of 


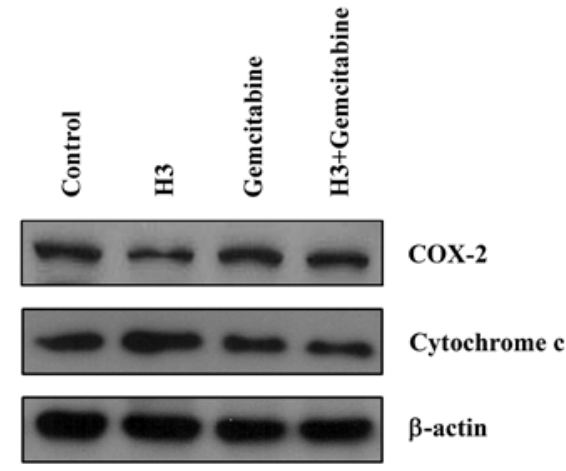

Figure 9. Effect of $\mathrm{H} 3$ and gemcitabine on the protein expression of COX-2 and cytochrome $c$ in tumor tissue. The expression levels of COX-2 (inflammation factor) and cytochrome $c$ (apoptosis factor) were determined by western blot analysis. $\beta$-actin was used as an internal control.

necrosis and erythrocytes in the tumor tissue was examined using H\&E staining. Significant necrotic cell death was detected in H3-treated tumor tissue compared to that in the control (Fig. 8A). Erythrocyte-containing cavities lined by tumor cells were also observed (Fig. 8B). These phenomena were also seen in co-treated and gemcitabine-treated tumor tissues but to a lesser degree. These data indicate that H3 treatment leads to significant necrotic cell death and erythrocyte-containing cavities in tumor tissue. Erythrocytes may enter apoptosis-like suicidal death or eryptosis, which is characterized by cell shrinkage and phosphatidylserine scrambling of the cell membrane. Eryptosis may also be triggered by an increase in cytosolic $\mathrm{Ca}^{2+}$, and the changes in $\mathrm{Ca}^{2+}$ mobilization could be linked to altered levels of COX-2 (21). Thus, the levels of apoptosis-associated factor (cytochrome $c$ ) and anti-apoptosis-associated factor (COX-2) were investigated. Proteins extracted from tumor tissue samples were analyzed by western blotting. In H3-treated samples, the expression of COX-2 was significantly reduced and the expression of cytochrome $c$ was strongly increased compared to that in the other treatments (Fig. 9).

\section{Discussion}

The use of current anticancer drugs can lead to many harmful side-effects such as resistance, metastasis and even death of normal cells (i.e., apoptosis). However, herbal mixture extracts could be a complementary medicine for anticancer drugs (15). Whereas, Western science and medicine focuses mainly on targeting specific malignant molecular mechanisms, complementary medicine using herbal mixture extracts employs a holistic approach that treats the entire human body (22). There is some dispute regarding the use of herbal mixture extracts since complex mixtures of medicinal herbs are employed in contrast to isolated single natural products. It is often suggested that herbal mixture extracts work synergistically to increase the therapeutic effect, while reducing the amount of adverse side-effects to healthy tissues (22). However, scientific data regarding the efficacy and safety of these complex herbal mixture extracts are often insufficient, so further research into this complementary medicine is needed $(7,12,13)$. The present study has shown that the herbal mixture extract $\mathrm{H} 3$ is a candidate for novel cancer therapies, and performs better in the selected tests than gemcitabine. There are some reports on each of the individual medicinal herbs, but the present study is the first to report the effect of this herbal mixture extract (23-25).

We investigated the effect of $\mathrm{H} 3$ as an alternative to gemcitabine. We also expected that combinatorial treatment (i.e. co-treatment) with $\mathrm{H} 3$-gemcitabine could have an enhanced effect against PANC1 cells. Thus, our experiments were performed in the presence of $\mathrm{H} 3$ only, gemcitabine only, or H3 and gemcitabine (co-treatment). We found that H3 suppressed cell growth by inducing G0/G1 cell cycle arrest (Figs. 1 and 2), unlike gemcitabine that is an anticancer drug which delays DNA synthesis through inhibition of the $\mathrm{S}$ phase of the cell cycle (8). We also observed that H3 induced greater early and late apoptotic cell death than gemcitabine, and that co-treatment resulted in a similar extent of early and late apoptotic cell death as with $\mathrm{H} 3$ treatment (Fig. 2C and D). It is known that most chemotherapeutic drugs kill cancer cells by inducing a programmed form of cell death (i.e. apoptosis) (26). Therefore, we hypothesized that $\mathrm{H} 3$ may be a possible therapeutic agent for pancreatic cancer or an adjuvant to gemcitabine treatment.

A subset of cancer cells called CSCs are oncogenic, and these cells are more recuperative than normal tumor cells. Thus, in their presence tumors relapse more easily after anticancer drug treatment. CSCs could be one of the best targets for cancer therapy (28). CSCs as therapeutic targets have been studied in various types of cancer such as breast, liver and prostate cancer (29-31). To investigate the effect of $\mathrm{H} 3$ on the characteristics of pancreatic CSCs, an SP analysis was conducted (Fig. 3). Most importantly, the average percentage of SP cells was slightly lower with $\mathrm{H} 3$ treatment and co-treatment than with gemcitabine treatment, indicating that the presence of $\mathrm{H} 3$ helps suppress SP cells. Additionally, the migratory ability of PANC1 cells was suppressed more greatly with $\mathrm{H} 3$ treatment and co-treatment than with gemcitabine only. This also indicates that the presence of $\mathrm{H} 3$ is critical for suppression of SP cells.

Since $\mathrm{H} 3$ induces apoptosis of PANC1 cells, we examined the mRNA levels of several apoptosis-related genes in the 3 different cell treatment groups (Fig. 5). The accumulation of CXCR4 mRNA, a gene related to metastasis and anti-apoptosis, and JAK2, another anti-apoptotic gene, was significantly decreased with all 3 treatments, suggesting that they each induce apoptosis efficiently. The mRNA levels of the anti-apoptotic protein XIAP decreased markedly by co-treatment with $\mathrm{H} 3$-gemcitabine, while levels decreased to a lesser degree with H3 or gemcitabine (data not shown). Due to their partial apoptotic resistance, it is known that pancreatic cancer cells often respond poorly to chemotherapy and/ or radiotherapy (27). These results indicate that H3 may be involved in the suppression of anti-apoptotic signaling, which could help overcome this resistance. Further studies are required to unveil the details of the relevant mechanistic pathway used by $\mathrm{H} 3$ for this purpose.

Since H3 suppresses SP cells, the mRNA accumulation of several stem cell-related genes was investigated (Fig. 6). The expression of ABCG2, which plays a role in multi-drug resistance, significantly decreased with co-treatment and 
gemcitabine treatment. The expression of POU5F1, which is related to the self-renewal of undifferentiated embryonic stem cells, was significantly reduced by $\mathrm{H} 3$ treatment and co-treatment. The expression of SOX2, which is a transcription factor that is essential for maintaining self-renewal or pluripotency of undifferentiated embryonic stem cells, was significantly decreased by co-treatment and gemcitabine treatment. Although there is no specific trend for the suppression of the 3 stem cell-related genes by the 3 different treatments, most of stem cell-related genes were suppressed to some extent by $\mathrm{H} 3$ as well as gemcitabine. This suggest that $\mathrm{H} 3$ is as potent as gemcitabine at suppressing pancreatic CSCs.

The in vivo study revealed that $\mathrm{H} 3$ and gemcitabine effectively suppress tumor growth (Fig. 7). However, contrary to the in vitro results, tumor growth in vivo was enhanced with co-treatment with $\mathrm{H} 3$-gemcitabine. This suggests that co-treatment with $\mathrm{H} 3$ may not be recommended for pancreatic cancer. Significant increases in necrotic cell death and erythrocyte-containing cavities were observed in H3-treated tumor tissue compared to the findings in other treatments (Fig. 8). The effectiveness of $\mathrm{H} 3$ as an anticancer agent for pancreatic cancer was also evidenced by western blot analysis which revealed that the expression of apoptosis-associated factor (cytochrome $c$ ) was upregulated and the expression of antiapoptosis-associated factor (COX-2) was downregulated in the tumors of mice having received this treatment (Fig. 9).

In conclusion, our experimental results show the remarkable effect of $\mathrm{H} 3$ in pancreatic cancer cells, cancer stem cells, and animal models. $\mathrm{H} 3$ is another example of an herbal mixture extracts which requires further studies to be developed into an anticancer therapeutic agent. Further study may be needed for detailed anticancer signaling pathway and, more importantly, application of $\mathrm{H} 3$ to other types of cancers.

\section{Acknowledgements}

The present study was financially supported by a Grant (B110053) from the Korean Health Technology R\&D Project, Ministry of Health \& Welfare, Republic of Korea.

\section{References}

1. Hidalgo M: Pancreatic cancer. N Engl J Med 362: 1605-1617, 2010.

2. Li D, Xie K, Wolff R and Abbruzzese JL: Pancreatic cancer. Lancet 363: 1049-1057, 2004.

3. Hong SK, Yang SY, Yin SH and Yang KX: RC-3095, a gastrin-releasing peptide receptor antagonist, synergizes with gemcitabine to inhibit the growth of human pancreatic cancer CFPAC-1 in vitro and in vivo. Pancreas 43: 15-21, 2014

4. Karakhanova S, Mosl B, Harig S, von Ahn K, Fritz J, Schmidt J, Jäger D, Werner J and Bazhin AV: Influence of interferon-alpha combined with chemo (radio) therapy on immunological parameters in pancreatic adenocarcinoma. Int J Mol Sci 15: 4104-4125, 2014.

5. Qu C and Chen Z: Antitumor effect of water decoctions of Taxus cuspidate on pancreatic cancer. Evid Based Complement Alternat Med 2014: 291675, 2014.

6. Laquente B, Lacasa C, Ginestà MM, Casanovas O, Figueras A, Galán M, Ribas IG, Germà JR, Capellà $G$ and Viñals $F$ : Antiangiogenic effect of gemcitabine following metronomic administration in a pancreas cancer model. Mol Cancer Ther 7: 638-647, 2008

7. O'Reilly EM: Adjuvant therapy for pancreas adenocarcinoma: Where are we going? Expert Rev Anticancer Ther 11: 173-177, 2011.
8. Burris HA III, Moore MJ, Andersen J, Green MR, Rothenberg ML, Modiano MR, Cripps MC, Portenoy RK, Storniolo AM, Tarassoff $\mathrm{P}$, et al: Improvements in survival and clinical benefit with gemcitabine as first-line therapy for patients with advanced pancreas cancer: A randomized trial. J Clin Oncol 15: 2403-2413, 1997.

9. Moore MJ, Goldstein D, Hamm J, Figer A, Hecht JR, Gallinger S, Au HJ, Murawa P, Walde D, Wolff RA, et al; National Cancer Institute of Canada Clinical Trials Group: Erlotinib plus gemcitabine compared with gemcitabine alone in patients with advanced pancreatic cancer: A phase III trial of the National Cancer Institute of Canada Clinical Trials Group. J Clin Oncol 25: 1960-1966, 2007.

10. Isayama H, Nakai Y, Yamamoto K, Sasaki T, Mizuno S, Yagioka H, Yashima Y, Kawakubo K, Kogure H, Arizumi T, et al: Gemcitabine and oxaliplatin combination chemotherapy for patients with refractory pancreatic cancer. Oncology 80: 97-101, 2011.

11. Khalil MA, Qiao W, Carlson P, George B, Javle M, Overman M, Varadhachary G, Wolff RA, Abbruzzese JL and Fogelman DR: The addition of erlotinib to gemcitabine and cisplatin does not appear to improve median survival in metastatic pancreatic cancer. Invest New Drugs 31: 1375-1383, 2013.

12. Wang S, Wu X, Tan M, Gong J, Tan W, Bian B, Chen M and Wang Y: Fighting fire with fire: Poisonous Chinese herbal medicine for cancer therapy. J Ethnopharmacol 140: 33-45, 2012.

13. Choi YK, Cho SG, Woo SM, Yun YJ, Park S, Shin YC and Ko SG: Herbal extract SH003 suppresses tumor growth and metastasis of MDA-MB-231 breast cancer cells by inhibiting STAT3-IL-6 signaling. Mediators Inflamm 2014: 492173, 2014.

14. Sikdar S, Mukherjee A, Ghosh S and Khuda-Bukhsh AR: Condurango glycoside-rich components stimulate DNA damageinduced cell cycle arrest and ROS-mediated caspase-3 dependent apoptosis through inhibition of cell-proliferation in lung cancer, in vitro and in vivo. Environ Toxicol Pharmacol 37: 300-314, 2014.

15. Yu J and Chen Q: Antitumor activities of Rauwolfia vomitoria extract and potentiation of gemcitabine effects against pancreatic cancer. Integr Cancer Ther 13: 217-225, 2014.

16. Kim MP, Evans DB, Wang H, Abbruzzese JL, Fleming JB and Gallick GE: Generation of orthotopic and heterotopic human pancreatic cancer xenografts in immunodeficient mice. Nat Protoc 4: 1670-1680, 2009.

17. Jung HJ, Pak PJ, Park SH, Ju JE, Kim JS, Lee HS and Chung N: Silver wire amplifies the signaling mechanism for IL-1beta production more than silver submicroparticles in human monocytic THP-1 cells. PLoS One 9: e112256, 2014.

18. Park SH, Sung JH, Kim EJ and Chung N: Berberine induces apoptosis via ROS generation in PANC-1 and MIA-PaCa2 pancreatic cell lines. Braz J Med Biol Res 48: 111-119, 2015.

19. Goodell MA, Brose K, Paradis G, Conner AS and Mulligan RC: Isolation and functional properties of murine hematopoietic stem cells that are replicating in vivo. J Exp Med 183: 1797-1806, 1996.

20. Wu J: Statistical inference for tumor growth inhibition $T / C$ ratio. J Biopharm Stat 20: 954-964, 2010.

21. Lang F, Gulbins E, Lerche H, Huber SM, Kempe DS and Foller M: Eryptosis, a window to systemic disease. Cell Physiol Biochem 22: 373-380, 2008.

22. Efferth T, Li PC, Konkimalla VS and Kaina B: From traditional Chinese medicine to rational cancer therapy. Trends Mol Med 13: 353-361, 2007.

23. Koppikar SJ, Choudhari AS, Suryavanshi SA, Kumari S, Chattopadhyay S and Kaul-Ghanekar R: Aqueous cinnamon extract (ACE-c) from the bark of Cinnamomum cassia causes apoptosis in human cervical cancer cell line $(\mathrm{SiHa})$ through loss of mitochondrial membrane potential. BMC Cancer 10: 210, 2010.

24. Zhang JW and Wei YH: Anti-cancer effects of Grailsine-Alglycoside isolated from Rhizoma Sparganii. BMC Complement Altern Med 14: 82, 2014.

25. Xie F, Zhang M, Zhang CF, Wang ZT, Yu BY and Kou JP: Anti-inflammatory and analgesic activities of ethanolic extract and two limonoids from Melia toosendan fruit. J Ethnopharmacol 117: 463-466, 2008.

26. Makin G and Hickman JA: Apoptosis and cancer chemotherapy. Cell Tissue Res 301: 143-152, 2000.

27. Li L and Leung PS: Use of herbal medicines and natural products: An alternative approach to overcoming the apoptotic resistance of pancreatic cancer. Int J Biochem Cell Biol 53: 224-236, 2014 
28. Abel EV and Simeone DM: Biology and clinical applications of pancreatic cancer stem cells. Gastroenterology 144: 1241-1248, 2013.

29. Kumar D, Shankar S and Srivastava RK: Rottlerin induces autophagy and apoptosis in prostate cancer stem cells via PI3K/Akt/mTOR signaling pathway. Cancer Lett 343: 179-189, 2014.

30. Suntharalingam K, Lin W, Johnstone TC, Bruno PM, Zheng YR, Hemann MT and Lippard SJ: A breast cancer stem cell-selective, mammospheres-potent osmium(VI) nitrido complex. J Am Chem Soc 136: 14413-14416, 2014.
31. Hashimoto N, Tsunedomi R, Yoshimura K, Watanabe Y, Hazama S and Oka M: Cancer stem-like sphere cells induced from de-differentiated hepatocellular carcinoma-derived cell lines possess the resistance to anti-cancer drugs. BMC Cancer 14: 722, 2014. 